\title{
Numerical coupling of Modelica and CFD for building energy supply systems
}

\author{
Manuel Ljubijankic ${ }^{1}$ Christoph Nytsch-Geusen ${ }^{1} \quad$ Jörg Rädler $^{1}$ \\ Martin Löffler ${ }^{2}$ \\ ${ }^{1}$ Universität der Künste Berlin, Lehrstuhl für Versorgungsplanung und Versorgungstechnik \\ Hardenbergstraße 33, 10623 Berlin \\ ${ }^{2}$ TLK-Thermo GmbH, Hans-Sommer-Str. 5, 38106 Braunschweig \\ nytsch@udk-berlin.de m.loeffler@ @tlk-thermo.de
}

\begin{abstract}
This paper presents an integrated method for the simulation of mixed 1D / 3D system models in the domain of building energy supply systems. The feasibility of this approach is demonstrated by the use case of a solar thermal system: the sub-model of a hot water storage is modeled as a detailed threedimensional CFD model, but the rest of the system model (solar collector, hydraulics, heat exchanger, controller etc.) is modeled as a simplified component-based DAE model. For this purpose, the hot water storage model is simulated with ANSYS CFD. This detailed sub-model is embedded in the solar thermal system model, which consists of component models of the Modelica library FluidFlow and is simulated with Dymola. The numerical coupling and integration of both sub-models is realized by the use of the co-simulation environment TISC. With a comparison of a pure Modelica system model and a mixed 1D / 3D system model of the same solar thermal system, advantages and disadvantages of both simulation approaches are worked out.
\end{abstract}

Keywords: Co-simulation; Mixed 1D/3D modeling; energy building and plant simulation

\section{Introduction}

Up to now, the simplified world of DAE (Differential Algebraic Equation) system simulation and the detailed world of CFD (Computational Fluid Dynamics) simulation have been two different "modeling cultures" in the domain of building energy supply systems. Users of component based DAE system simulation tools/approaches like Modelica
[1], MATLAB/Simulink [2], TRNSYS [3] analyze the transient behavior of complex energy system models, which include simplified physical submodels of the energy supply systems, models for the supplied buildings and models for the control algorithms of the energy management. Because the complexity of these models is reduced (typically some hundred up to 100,000 model variables), the time periods in simulation experiments can be a week, a month or a year.

In comparison to the simplified systems models, detailed 3D CFD models are used to optimized the thermal comfort of a room (e.g. to find suitable positions of inlet and outlet air passages, which guarantee comfortable local air temperatures and air velocities) or to optimize the flow conditions and the heat transfer within a building services component (e.g. to design the inner geometry of a heat water storage). The second type of models uses highly discretized Finite Element Models (FEM) ore Finite Volume Models (FVM) with up to several million equations. For this detailed models, the used time period in transient simulation experiments can be - restricted by the currently existing numerical power - some seconds up to some days.

The basic idea of this article is to combine both worlds to a numerical integrated simulation approach for building energy supply systems (compare with Figure 1): the DAE simulation tool (e.g. Dymola) produces with the help of its - component-based one-dimensional Modelica model transient ("intelligent") boundary conditions for the detailed threedimensional CFD tool/model and vice versa. In this way, the most interesting part(s) of a system model can be analyzed on a more detailed level, wherein the system relationships are fully taken into account. 


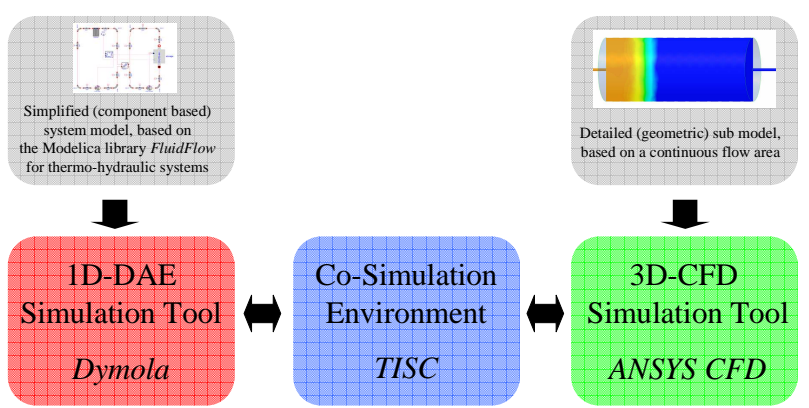

Figure 1: Numerical integrated simulation approach for DAE / CFD modeling of building energy supply systems

The numerical data exchange and the synchronization of the numerical solvers of several simulation tools are realized by the use of the co-simulation environment TISC [12]. In this procedure, it is very important to use "appropriate models" from the DAE- and the CFD-world, this means the models use a comparable physics, and they produce similar results on an aggregated level. Preliminary studies on this have been undertaken by the authors $[14,15]$.

\section{Use case: Solar thermal system}

For doing the comparative system simulation studies about the numerical coupling between the DAEapproach of Modelica and the CFD-approach, a solar thermal system for warm water production was used as a reference system (see Figure 2).

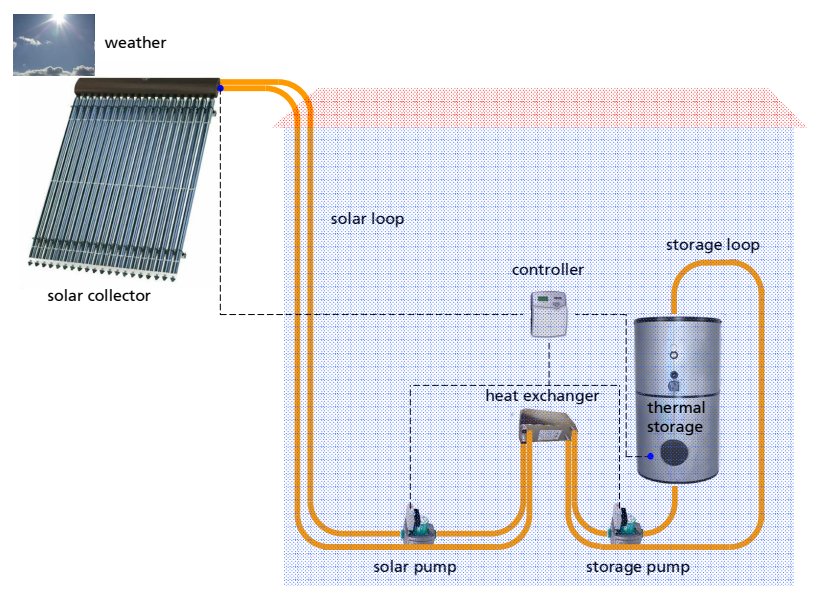

Figure 2: Used solar thermal system for the simulation studies

The most important components of the solar thermal system are an evacuated tube collector (type Viessmann VITOSOL $200 \mathrm{~T}$ ) with an aperture area of $3.17 \mathrm{~m}^{2}$ and a hot water storage with a volume of 400 liter. The roof collector is aligned to the south and tilted with an angle of $30^{\circ}$. Here, the vertical distance between the roof and the storage is $10 \mathrm{~m}$. The cylindrical shaped storage has a height of $1.45 \mathrm{~m}$ and a diameter of $0.59 \mathrm{~m}$ and is isolated with 100 $\mathrm{mm}$ insulation $(\lambda=0.06 \mathrm{~W} /(\mathrm{m} \cdot \mathrm{K}))$. An external plate heat exchanger $(\mathrm{k} \cdot \mathrm{A}=1,000 \mathrm{~W} / \mathrm{K})$ transfers the produced thermal energy from the solar loop to the storage loop. With the help of a two-point-controller the solar pump and the storage pump are switched on (mass flow rate $0.0264 \mathrm{~kg} / \mathrm{s}$ ), if the collector outlet temperature is $4^{\circ} \mathrm{K}$ higher than the temperature in the lower part of the storage (hysteresis of $5^{\circ} \mathrm{K}$ ). All hydraulic components of the solar thermal system are connected with copper pipes with an inside diameter of $26 \mathrm{~mm}$, a wall thickness of $1 \mathrm{~mm}$ and an insulation thickness of $30 \mathrm{~mm}(\lambda=0.035 \mathrm{~W} /(\mathrm{m} \cdot \mathrm{K})$. For the climate boundary condition Meteonorm [16] weather data from Hamburg (Germany) were used. In the simulation scenario the load process for the thermal water storage over a time period of $24 \mathrm{~h}$ (86,400 seconds) during a summer day were analyzed. At the beginning of the load process all the fluid temperatures in the collector, in all pipes and in the storage shall be $20^{\circ} \mathrm{C}$.

\section{System simulation with Modelica}

To obtain a reference system for the evaluation of the coupled Modelica/CFD-model, in a first step the solar thermal system was modeled as a pure Modelica model. For this purpose, the FluidFlow-library was used.

\subsection{Modelica FluidFlow library}

The Modelica-library FluidFlow is being developed at UdK Berlin for thermo-hydraulic network simulation [4]. The main application field of this library is the modeling of solar thermal systems, HVAC (Heating, Ventilation and Air-Conditioning)-systems and district heating/cooling systems.

The FluidFlow-library comprises a set of "ready-touse" standard hydraulic models, such as pipes, elbows, distributors and pumps. Further, the library includes more specialized models from several domains (compare with Figure 3), such as solar thermal technologies (collector models), thermal storage technologies (storage models) or energy transformation technologies (e.g. models of heat exchangers, absorption chillers and cogeneration plants).

The weather data sets are read and interpolated with a new developed Modelica component, based on the ncDataReader2 library, which provides access to external data sets as continuous functions [5]. 


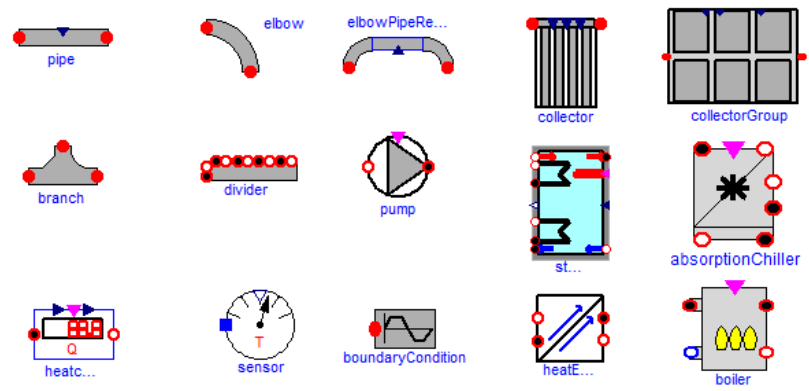

Figure 3: Standard models (left) and specialized models (right) of the thermal-hydraulic Modelica library FluidFlow.

Up to now the main application field of the FluidFlow-library was the modeling and simulation of complex energy supply systems (heating and cooling energy) for new planned city districts with residential buildings in Iran [6].

\subsection{Modeling as pure Modelica system model}

Figure 4 shows the system model of the solar thermal system from the use case, solely modeled with sub-components of the Modelica FluidFlow-library.

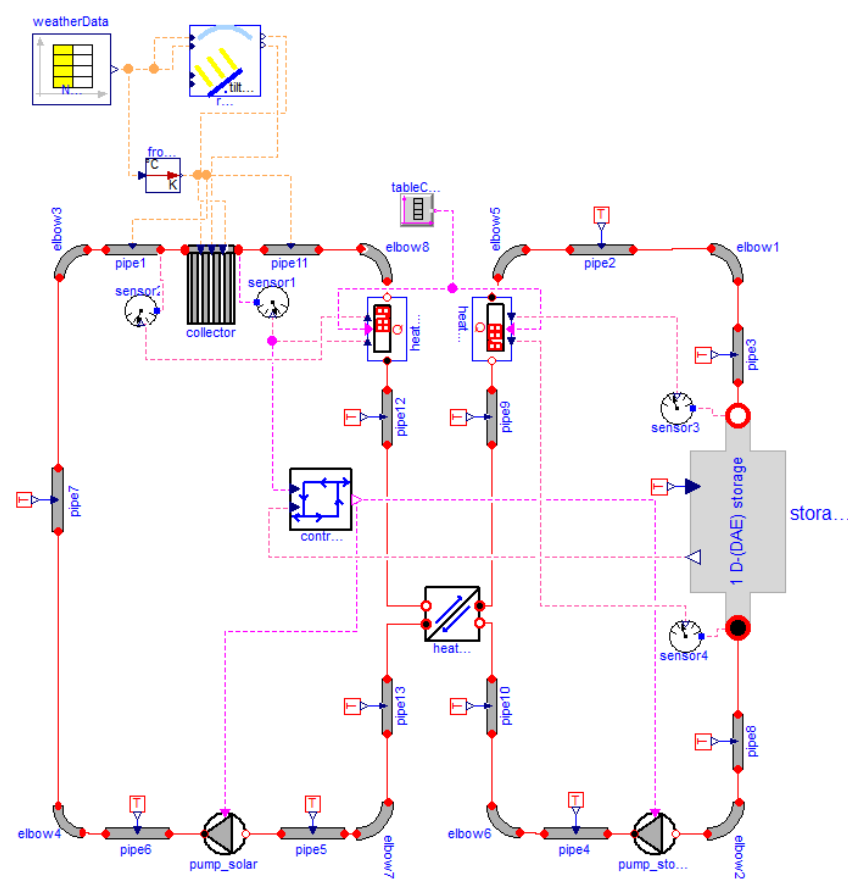

Figure 4: Solar thermal system, modeled as system model with pure Modelica sub-components

The used physical models (solar collector, pipes, external heat exchanger, hot water storage) were validated from [7]. All the pipes were parameterized in a way that a minimum of 1 numerical node per $1 \mathrm{~m}$ pipe length can be ensured. The hot water storage model is divided into 10 thermal horizontal zones. This modeling approach leads to a system model with 721 time variables. With the symbolic reduction algorithm of the used simulation tool Dymola [8], the DAE-system could be reduced to 419 time varying variables.

In order to define suitable and comparable interfaces to the Modelica/CFD system model, a subsystem for the hot water storage and its boundary conditions (connection pipes, inlet boundary conditions, models for the pressure losses for the flow dilation and contraction) were introduced (compare with Figure 5).

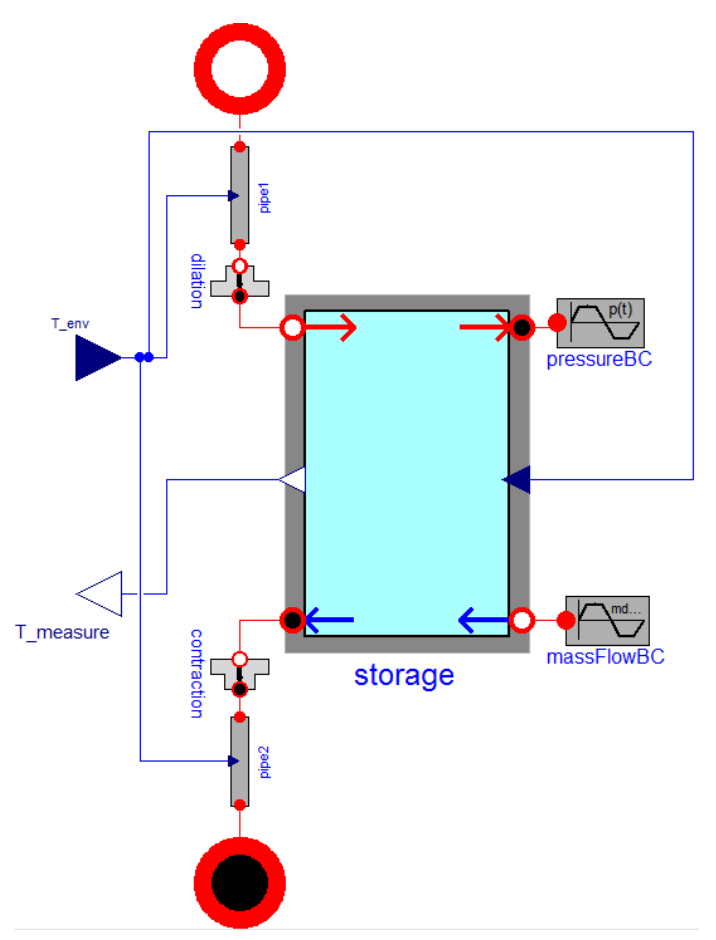

Figure 5: Modelica sub-system for the thermal storage and its boundary conditions

\section{Modelica system simulation with an integrated CFD sub-model}

\subsection{Modeling and simulation with ANSYS CFD}

In order to determine the model state at any point of the volume of the hot water storage (e.g. temperatures, velocities, pressures), the three-dimensional CFD method was used. In our case, the fluid region of the hot water storage is modeled with ANSYS CFD Release 12.1 [9], which works with CFD algorithms, based on the Finite Volume Method (FVM). The FVM method calculates approximated solutions of the partial differential equation system, which describes the transport process of momentum, mass and 
heat transfer within the flow region (Navier-Stokes equations):

Continuity equation:

$$
\frac{\partial \rho}{\partial t}+\nabla \bullet(\rho \mathbf{U})=0
$$

Three momentum equations (vector notation with the Nabla-operator for the three Cartesian coordinates):

$$
\frac{\partial(\rho \mathbf{U})}{\partial t}+\nabla \bullet(\rho \mathbf{U} \otimes \mathbf{U})=-\nabla p+\nabla \bullet \tau,
$$

Total energy equation:

$$
\begin{aligned}
& \frac{\partial\left(\rho h_{t o t}\right)}{\partial t}-\frac{\partial p}{\partial t}+\nabla \bullet\left(\rho \mathbf{U} h_{t o t}\right) \\
& =\nabla \bullet(\lambda \nabla T)+\nabla \bullet(\mathbf{U} \bullet \tau) .
\end{aligned}
$$

For each element of the flow region a discretized form of the mentioned 5 partial differential equations is calculated from the ANSYS CFD numerical solver.

\subsection{D CFD model of the hot water storage}

An adequate three-dimensional model of the hot water storage has to fulfill several aspects:

1. The discretization of the fluid regime has to be fine enough to limit the numerical error. For this purpose, the size of the elements has to be adapted to the local geometries und the local velocities.

2. The CFD model has to be fast enough for a coupled transient simulation.

3. The location of the interface planes between the three-dimensional CFD fluid regime and the one-dimensional Modelica fluid regime have to be chosen in a way, that the fluid flow at the interface point can take place without a significant disturbance, which can be induced by the inner fluid flow pattern of the storage.

For this reason, the fluid regime of the cylindrical storage was supplemented by two connection pipes with a length of $0.275 \mathrm{~m}$. This necessary length was established by preliminary CFD flow pattern tests with a typical mass flow from the storage pump $(0.026 \mathrm{~kg} / \mathrm{s})$. The compromise between a needed accuracy and a desired numerical performance is a mesh with all in all 21,904 numerical nodes $(85,230$ finite volume elements). Hereof 5,440 numerical nodes (5,370 finite volume elements) are used for the connection pipe models and 16,464 numerical nodes (79,860 finite volume elements) for the storage model (compare with Figure 6). The used turbulence model was a laminar model, because the range of values of the Reynolds number of the fluid regime, which can be assigned to the connection pipes, reaches from of $1,290\left(20^{\circ} \mathrm{C}\right)$ up to $2,230\left(47^{\circ} \mathrm{C}\right)$.

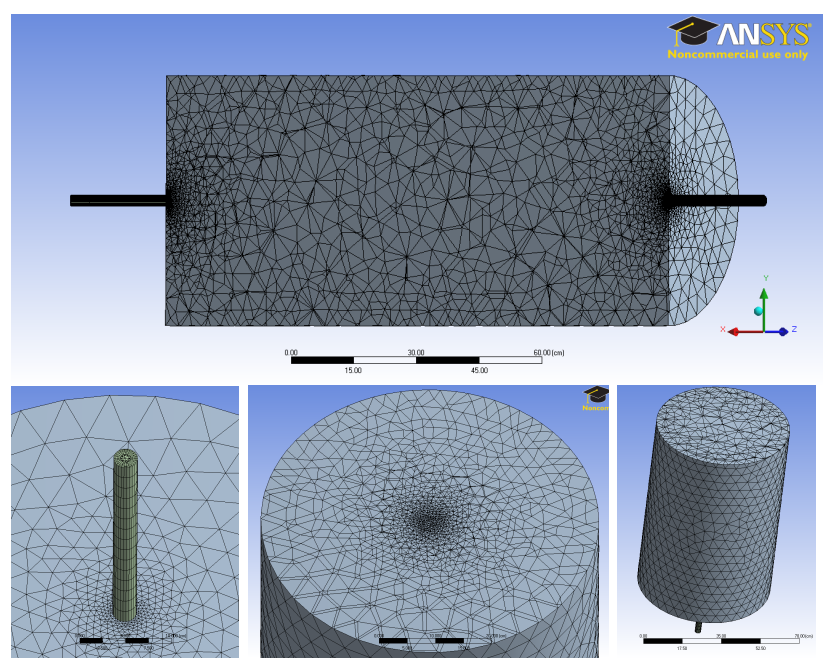

Figure 6: Adapted Mesh of the finite volume storage model: longitudinal section (above), horizontal view on the storage with connection pipe (below left), horizontal sections close to the inlet (below middle) and in the middle of the storage (below right)

\subsection{Numerical tool coupling by TISC}

TISC [12] - the TLK Inter Software Connector - is a co-simulation environment for coupling different simulation programs. The software is platform independent and uses TCP/IP-sockets for communication. TISC provides interfaces to 1-D and 3-D simulators (like MATLAB/Simulink, Dymola, KULI, CFX, Star-CD) and more abstract interfaces written in $\mathrm{C}, \mathrm{C}++$, Java and Fortran (see Figure 7).

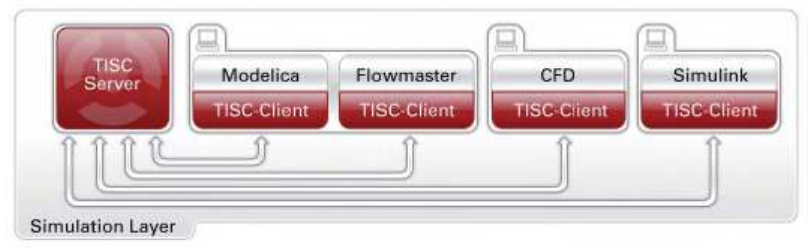

Figure 7: TISC simulation environment

Tool coupling has several advantages (see [10]). The best tool can be chosen to describe all parts of a system. Present software and expert knowledge can be used for modeling complex systems from diverse 
physical and engineering domains (see [11]). In some cases, it also makes sense to break down a model or system into several sub-systems to decouple the time steps and accelerate the simulation. Using TISC makes it also possible to integrate transient boundary conditions from different specialized simulation tools. For example, the input and output data from a detailed FEM or CFD simulation tool are available for a DAE Modelica model in Dymola and vice versa. Distributed computation of a system on several cores also provides the opportunity to parallelize a simulation calculation and get more computation performance.

The TISC environment is divided in two layers, the Simulation-Layer and the Control-Layer. The Control-Layer is responsible for starting and parameterizing all models at simulation start. It is also possible to configure a set of simulations and let them run automatically one after another in batch-mode. This is helpful for using computer resources efficiently.

After a simulation has started, the SimulationLayer is responsible for handling data-exchange and synchronization. Using the Control-Layer is optional and a distributed simulation can be performed using only the Simulation-Layer.

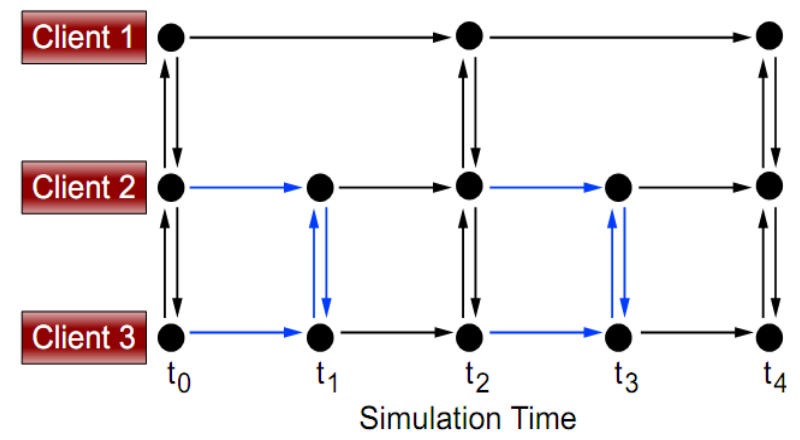

Figure 8: TISC synchronization scheme

TISC supports sequential ("explicit") synchronization, while parallel ("implicit") synchronization (see [13] and Figure 8) is often used. When using parallel synchronization all models are being calculated simultaneously. With increasing number of models this leads to a major increase in simulation speed.

TISC uses fixed step-sizes for data-exchange between the models and the server. The synchronization rate of the models has a highly influence on the total simulation time, because every time a model gets synchronized with the TISC server, depending on the used simulation program, an event is generated and a convergent solution for the model has to be found again. With an increasing synchronization rate for system models with relative large time constants, the number of synchronization events can be reduced and the simulation experiment can be relevant accelerated. It is also possible, that each model uses its own synchronization rate.

\subsection{Coupled Modelica / CFD system model}

Figure 9 illustrates the coupled Modelica / CFD system model of the solar thermal plant, where the onedimensional DAE hot water storage model was substituted by a container model, which includes the coupled ANSYS CFD model and the corresponding TISC coupling components.

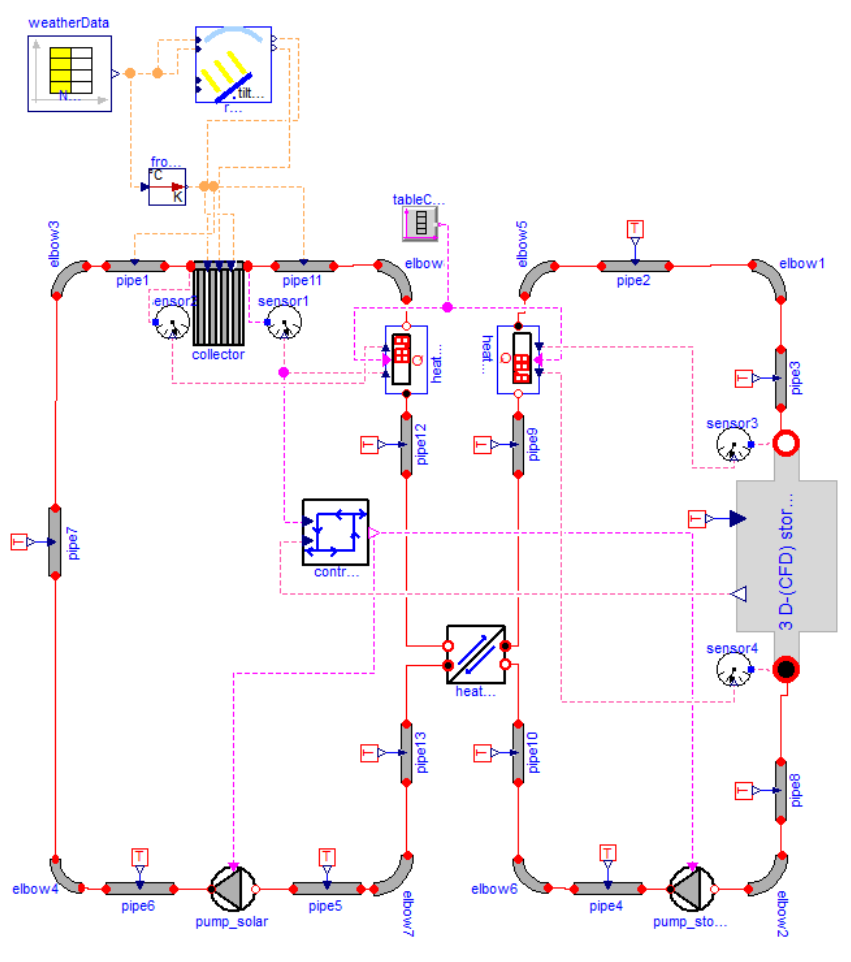

Figure 9: Solar thermal system, modeled as system model with coupled Modelica and CFD subComponents

Beside the interfaces for the inlet and outlet mass flow, the Modelica / CFD sub-system models has further interfaces to the storage environment temperature and to the temperature sensor within the 3D fluid regime, which is axially positioned $7.3 \mathrm{~cm}$ above the bottom of the storage. The hot water storage model has to be exchanged both temperature values with the "Modelica world" to determine the heat loss through the storage insulation and to provide the measured storage fluid temperature as an input for the two point controller model (compare with Figure 10). 


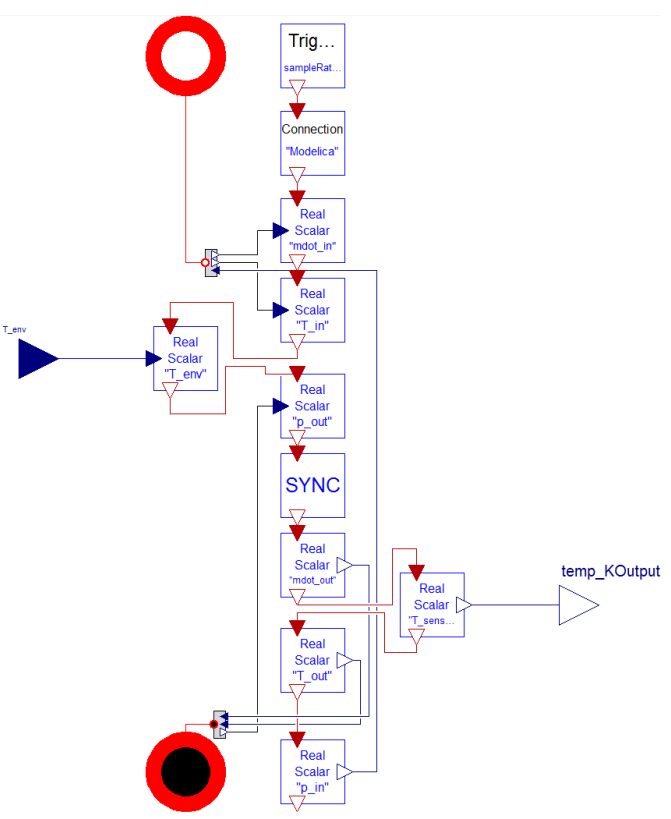

Figure 10: Modelica / CFD sub-system for the thermal storage

\section{Comparative results of both simu- lation approaches}

The Simulation experiment for the pure Modelica system model was performed with Dymola 7.4, using the DASSL solver with a tolerance of $1 \mathrm{e}-4$. The simulation model runs fast and needs only some seconds simulation time for one day real time.

In comparison to this, the coupled Modelica / CFD system model runs approximately half as fast as real time $(\approx 50$ hours simulation time). For this simulation experiment, an Apple MacPro workstation with 8 Xeon cores $(2.8 \mathrm{GHz})$ and $32 \mathrm{~GB}$ RAM with the operation system Linux OpenSuse 11.2 was used. Doing this, ANSYS CFD used 8 cores for the parallelized CFD-simulation and Dymola used a separate core for the monolithic DAE-simulation on another Windows workstation. The synchronization rate of TISC was set on 1 second.

Figures 11 to 14 illustrate the run of the curves for the most important state and process variables of the solar thermal system for a summer day in June (174th day of the year).

Figure 11 shows the beam, diffuse and total solar irradiation on the tilted solar collector. The value for the total radiation exceeds $800 \mathrm{~W} / \mathrm{m}^{2}$ at midday.

Figure 12 illustrates the inlet and outlet fluid temperatures of the solar collector and the outside air temperature for both simulation approaches. The basic running of the temperatures values is similar (temperature levels, switching-on and -off events etc.), but the values of the system with the CFDstorage model are more differentiated. The most important reason for these differences consists in the non-existent momentum model within the DAE storage model and its restricted space resolution to one dimension.

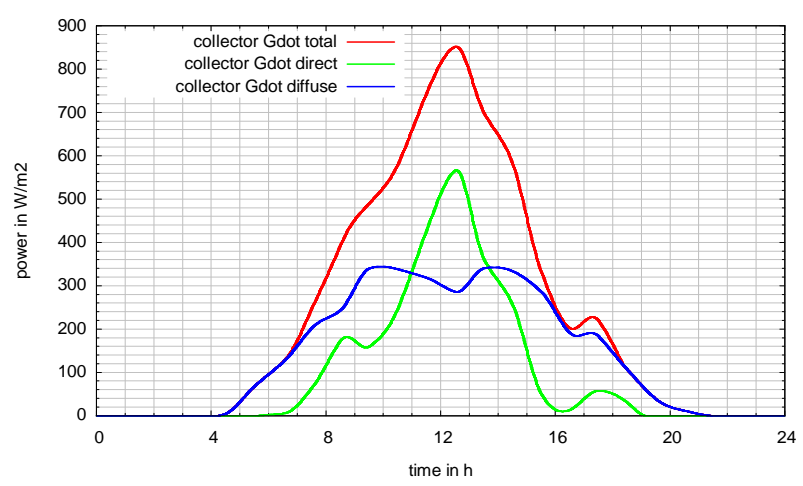

Figure 11: Direct, diffuse, total solar irradiation on the tilted collector

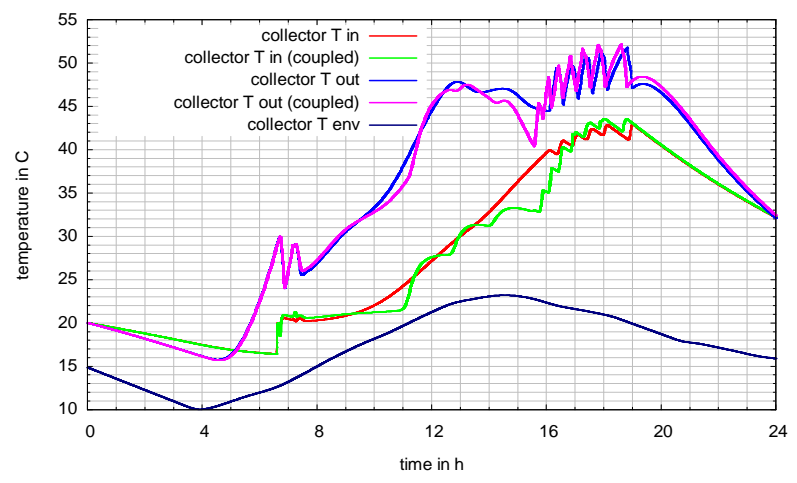

Figure 12: Collector input and output temperature for the pure Modelica system model and for the coupled Modelica / CFD system model
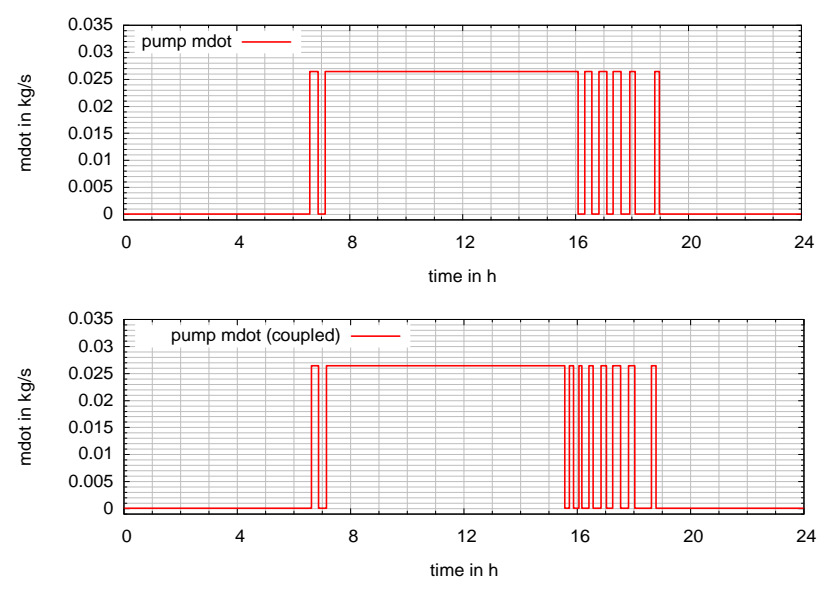

Figure 13: Mass flow of the collector and the storage pump for the pure Modelica system model (above) and the coupled Modelica/CFD system model (below) 
Figure 13 demonstrates the switching characteristic of the two-point controller at hand of the timeline of the mass flow, transported by the pumps. The basic pattern of the mass flows for the pure Modelica model and the mixed Modelica / CFD model is similar until 16 o'clock, when the solar irradiation intensity drops significantly. Then, differences in the controller behavior are clearly visible.

Figure 14 shows the inlet and outlet fluid temperatures of the connection pipes between the storage sub-model and the rest of the solar thermal system model (indices plane in, plane out). Further, 10 representative temperatures within the storage fluid volume are represented. For comparing the 10 vertical temperature values of the pure DAE Modelica model with the detailed temperature field of the CFD model, integrated mean values over 10 horizontal volumes were used (indices volume 1 to volume 10).
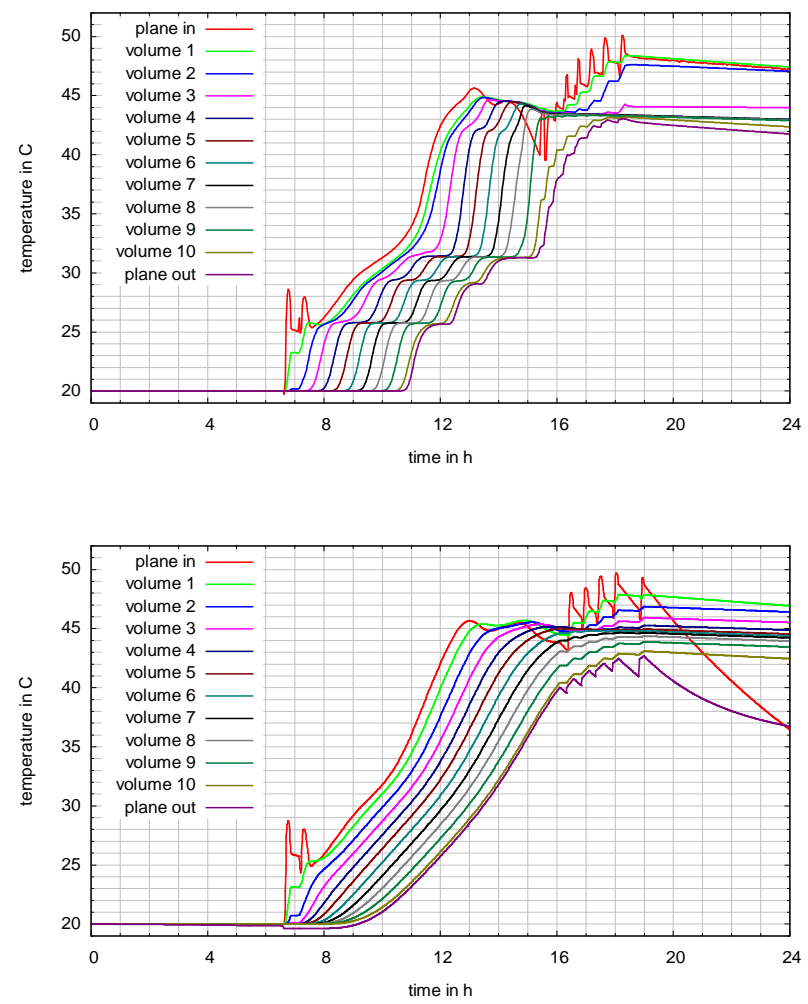

Figure 14: Inlet, outlet and layer temperatures of the thermal storage for the CFD/FVM-model (above) and the Modelica/DAE-model (below)

The temperature levels in both storage models increase during the day parallel to the stored thermal energy. The impact of the switch-on/switch-off characteristic of the mass flows on the storage temperature values developing can be clearly recognized during the morning hours and the evening hours. The CFD storage model shows a significantly more complex behavior: If the stored thermal energy flux changes or the incoming mass flow switches between zero and its maximum value, the CFD model shows an immediate reaction, because the momentum transport and the natural convection are part of the CFD algorithm.
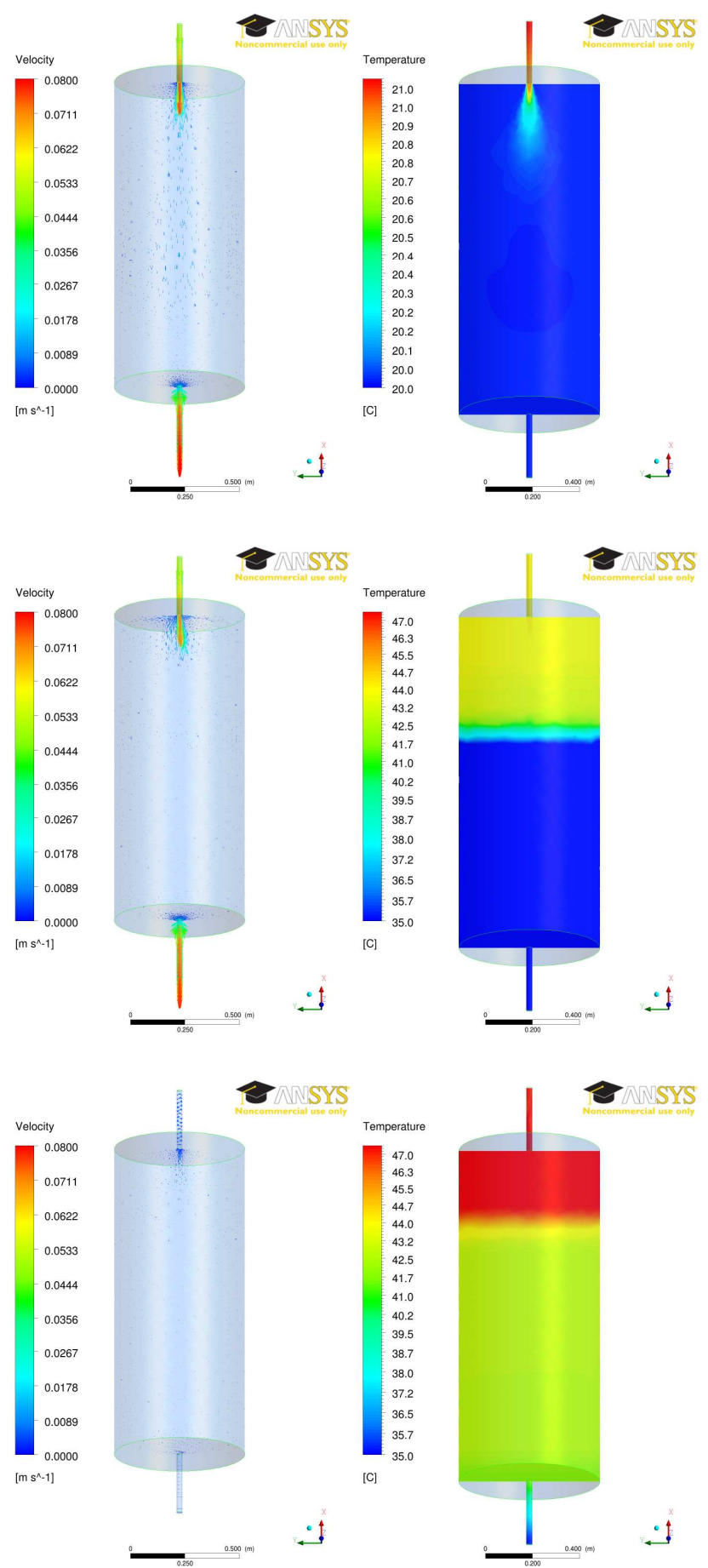

Figure 15: Vertical section of the velocity field (left) and temperature field (right) after the first switch on event at 6:44 (above), at 13:00 (in the middle) and at 24:00, calculated by the coupled CFD/Modelica model 
An interesting phenomenon can be observed at the point plan in after sunset $(\rightarrow$ mass flow of the storage pump equal to zero): During this time period, the DAE Modelica storage model shows an obvious temperature drop, while the temperature level on the same point of the CFD storage model has only a small decline. The reason for this difference lies in the natural convection effect, induced by the comparatively heat loss effect for the fluid in the small connection pipe in contrast to of the heat loss effect for the fluid within the storage. As a result, the natural convection compensates the increased heat loss of the connection pipe by transporting additional thermal energy from the highest (and hottest) layer of the storage. This effect leads also to the greatest velocity in the region of the inlet connection pipe. The same phenomenon with the reinforced heat loss and the resulting induced convection can be recognized within the vertical sections of the temperature field and the velocity field at the end of the day (24 o'clock, compare with the third picture in Figure 15 and its enlargement in Figure 16).

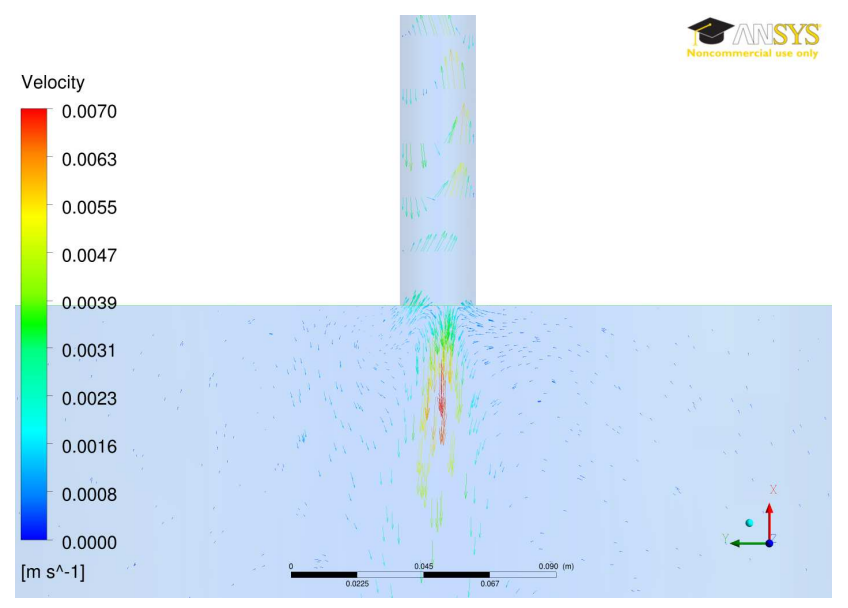

Figure 16: Natural convection phenomenon (velocity field) at the inlet of the hot water storage CFD model at 24:00

Figure 17 illustrates the comparison of the calculated heat energies (supplied heat from the collector model and the inducted heat into the hot water storage) for the pure Modelica system model and for the coupled Modelica / CFD system model as integrated power values. During the whole load process there is only a very small difference between both simulation approaches. The differences between the gained energy from the collector and the inducted energy into the storage are the thermal losses of the hydraulic components.

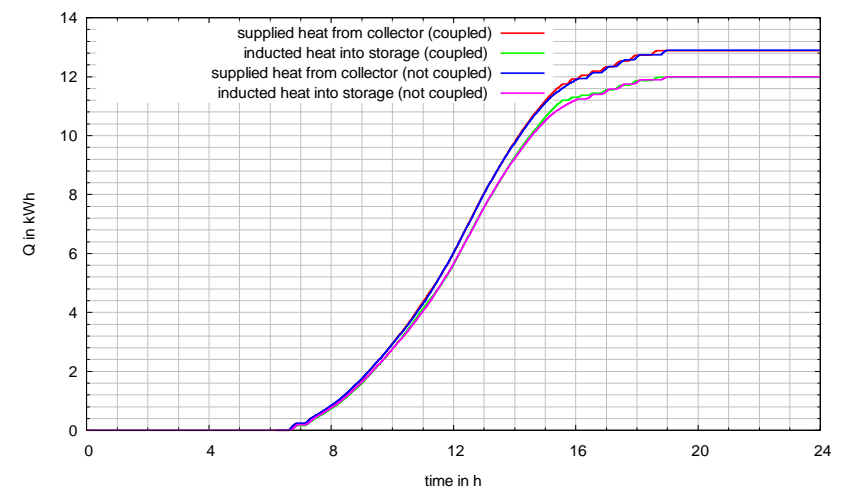

Figure 17: Supplied heat from the collector model and inducted heat into the hot water storage for the pure Modelica system model and for the coupled Modelica / CFD system model

\section{Summary and Outlook}

It could be demonstrated by the example of a solar thermal plant, that the mixed DAE / CFD simulation approach works. This, the pure Modelica system model showed a qualitatively similar behavior (timelines of the temperature and of the discrete controller events) and quantitative nearly identical energy values in comparison to the mixed model. In addition, the detailed CFD sub-model of the hot water storage allows analysis for detailed questions (e.g. to find an optimized temperature sensor position or for studying convection phenomena) with full consideration of the surrounding system model. A sufficiently discretized CFD model requires at a up-to-date computer hardware computing times twice as long as realtime.

The next steps of the research will be a detailed analysis of the pressures losses within the different parts of the system (e.g. pressure fluctuations during discrete controller switching events). In addition further system models with more than one CFD submodel (e.g. a collector CFD sub-model and a storage CFD sub-model) will be considered. For the acceleration of the computation time of the coupled system model, the optimization of the numerical coupling parameters (e.g. the synchronization rate between both simulation tools) and parameter studies with different fine discretized meshes of the hot water storages will be considered. 


\section{References}

[1] Homepage Modelica Association: http://www.modelica.org

[2] Homepage MATLAB/Simulink: http:// www.mathworks.com/products/simulink

[3] Homepage TRNSYS: http://www.trnsys.com

[4] M. Ljubijankic, C. Nytsch-Geusen: Thermohydraulische Simulation solarthermischer Systeme mit Modelica. In Proceedings: 18. Symposium Thermische Solarenergie, OTTITechnologiekolleg, Regensburg, 2008.

[5] Homepage ncDataReader: http://www.j-raedler.de/projects/ncDataReader2

[6] Ederer, K.; Huber, J.; Nytsch-Geusen, C.; Seelig, S.; Unger, S.; Wehage, P.: Konzeption und Planung solarunterstützter Energieversorgungssysteme für New Towns im Iran. In Tagungsband: 20. Symposium Thermische Solarenergie in Staffelstein, OTTITechnologiekolleg, Regensburg, 2010.

[7] C. Nytsch, M. Poli, T. Schneider: Messtechnische Untersuchungen an einer solarthermischen Versuchsanlage zur Validierung der solartechnischen Modelle der Simulationsumgebung SMILE. In Proceedings: 10. Symposium Thermische Solarenergie in Staffelstein, OTTI-Technologiekolleg, Regensburg, 2000.

[8] Homepage Dymola: http://www.3ds.com/products/catia/portfolio/dymola

[9] Homepage ANSYS CFD: http://www.ansys.com/products/fluid-dynamics/cfd/

[10] Kossel, R.; Tegethoff, W.; Bodmann, M.; Lemke, N.: Simulation of Complex Systems using Modelica and Tool Coupling. In: Proceedings of the 5th International Modelica Conference, Vienna, Austria, Modelica Association, September 2006, 485 - 490.

[11] Kossel, R.; Försterling, S.; Tegethoff, W.: Einsatz hybrider Simulationstechnik für die Bewertung mobiler Heiz- und Kühlkonzepte. In: Brill, U. (Hrsg.) ; Haus der Technik (Veranst.): Wärmemanagement des Kraftfahrzeugs VI Haus der Technik, ExpertVerlag, Juni 2008 (Haus der Technik Fachbuch 93). - ISBN 978-3-8169-2820-1, S. $150-162$.

[12] Kossel, R.; Correia, C.; Loeffler, M.; Bodmann, M. ; Tegethoff, W.: Verteilte Systemsimulation mit TISC. In: ASIM-
Workshop 2009 in Dresden mit integrierter DASS'2009, 2009.

[13] W. Puntigam et al., Transient Co-Simulation of Comprehensive Vehicle Models by Time Dependent Coupling. In: SAE 2006 Transaction Journal of Passenger Cars: Mechanical Systems, ISBN 978-0-7680-1838-7, pages $1516-1525$.

[14] M. Ljubijankic, C. Nytsch-Geusen, S. Unger: Modelling of complex thermal energy supply systems, based on the Modelica-Library FluidFlow. Proceedings 6th International Modelica Conference. In Proceedings: 7th International Modelica Conference, 20./22. September, Como, 2009.

[15] M. Ljubijankic, C. Nytsch-Geusen: Combining different levels of detail in modelling for an improved precision of HVAC plant simulation. In Proceedings: Building Simulation 2009, International Building Performance Simulation Association, Glasgow, 2009.

[16] Homepage Meteonorm: http://www.meteonorm.com 